\section{A vision for health system reform in the Americas ${ }^{1}$}

\author{
George A. O. Alleyne
}

\begin{abstract}
Many such terms as "health sector reform" and "health system reform" are used interchangeably and are perhaps misinterpreted. Therefore, it is well to begin with some definitions and in this way clarify what I mean when I use any of these terms. I understand the health sector to cover all the different kinds of activities within a society that are undertaken purposely in order to protect and promote health, as well as to cure and care for the ill. That part of society that has these activities as its main and principal concern is designated the health sector. Thus, while education has a great deal to contribute to health, those activities carried out there cannot be included under the health sector.
\end{abstract}

The health system we will discuss comprises a set of components within the sector that work together in an articulated manner to provide certain outputs. Those components are the financial, human, physical, organizational, and informational resources that function in an articulated and coordinated manner such that the effect of their actions or contributions is greater than the sum of the individual parts. It is not helpful to consider the contribution of one of these components to some final end without taking account of the interaction with other parts of the system. I therefore think it is rather disingenuous to consider the contribution of human resources, for example, without thinking that the informational and physical resources must interact with them in a substantial manner.

I will refer principally to the formal part of the system, thereby omitting all those activities that touch on health and are carried out domestically or through folk practices. Even though the formal part of the system is very much the smallest, accounting for about $20 \%$ of the health activities, it is the part that is of most concern to us in this setting, where we are addressing mainly public policy and the reform that may take place.

The final point I would make here is that I take the health system and its various subsystems as being essentially social in nature, and they therefore entail commitment to some form of social justice. Because health systems are social systems, they should seek to reduce the inequalities of health outcomes in the populations they cover. Similarly, because they employ societal resources, health systems should also be as efficient as possible. The output or end of the health system of a country is to improve the health of citizens through 
promotion of health, prevention of illness, cure, care, and rehabilitation

As we consider the future of health systems and how they should be reformed, we must understand that they have never and will never exist in a vacuum. They are a product of the culture, geography, and history of a people. There is a limit to how much one system that has different cultural roots can be grafted onto another and be expected to flourish and be successful. I will focus mainly on Latin America and the Caribbean, and I will begin by mentioning the differences imposed by size and geography as shown in the island states of the Caribbean. The types of decentralized systems that derive from size of territory and the traditions of a federalist State cannot be sustained in the Caribbean exactly as they appear elsewhere. Similarly, the cultural orientation to British systems makes it difficult to embrace systems that derive from the different form of social organization and individualism that characterizes the North American society.

The health systems of Latin America in general include hybrid versions of the Bismarckian model, in which the social security system counts on funds from the employer and the employee, and is also supplemented with public funds to varying degrees. In addition, there are parallel private systems and systems operated by ministries of health. A remarkable feature is the segmentation of the financing and provision of health services, with the three dominant players being the ministry of health, social security, and the private sector, in terms of both financing and care. This fragmentation represents a major challenge, and to some degree inhibits the systems from discharging in the most efficient manner possible the two goals that seem to confront all systems. The first of these goals has two elements: 1) equity, in that all citizens should have access to some basic minimum of health care through the health services, and 2) that the payment for protection against being socially and economically devastated by illness should not be based on individual risk and economic competence. The other major goal is the need for cost control in absolute terms, as well as in relation to providing quality services at minimum cost.

Improvement in health status is commonly seen as a consequence of development. The perception that the population was not participating fully in national development perhaps led the presidents and heads of state at the Summit of the Americas in Miami in 1994 to include among their principles the following:

It is politically intolerable and morally unacceptable that some segments of our population are marginalized and do not share fully the benefits of growth.
Because this marginalization was evident in health, they adopted the Resolution on Equitable Access to Basic Health Services, and they charged the Pan American Health Organization (PAHO) with monitoring the necessary process of reforming health systems.

As a part of that monitoring process it was necessary to examine some of the challenges that face the systems. The most obvious is that of coverage by the services. It has been estimated, and I have cited these figures, that $25 \%$ of the population of Latin America and the Caribbean lack basic health services. But it is really very difficult to establish precise figures for coverage by the services, because it depends very much on the indicator used and the type of services. I have adopted a division of the services into those that are supply driven and those that are demand driven. In general, the supply-driven services are those that tend to have the highest positive externalities. Thus the Region of the Americas has achieved immunization coverage rates of over $90 \%$ for the basic vaccines of the Expanded Program on Immunization, and there is every expectation that the same will occur for the newer vaccines, such as those against hepatitis and meningitis. To a smaller degree, there has been a marked increase in coverage of water supply both to the urban and rural areas. The possibility of dealing with the problem of tuberculosis is heightened because once diagnosed the treatment is supply driven. The degree of inequality is reduced or low with these services.

It is with the personal care services, which are demand driven, that we perceive the great inequalities. The results are shown in health outcomes. The care for patients with chronic diseases that need to be diagnosed, treated, and followed up carefully is remarkably uneven and shows many inequalities in terms of outcome. Only about $60 \%$ of eligible women use family planning services. Maternal and infant mortality rates are higher among marginalized groups, including the poor, rural inhabitants, and indigenous populations. Whenever the studies have been done, mortality and morbidity from a wide range of causes are higher among indigenous populations, who suffer from the combination of ethnicity, geographical isolation, poverty, and lack of political influence. Although it is impossible to be precise, direct observation tells us that there are very large numbers of persons without access to basic services.

Cost is another challenge. The cost of health care services is rising steadily in Latin America and the Caribbean. The percentage of gross domestic product spent on health was $5.8 \%$ in $1980,6.9 \%$ in 1990 , and $7.3 \%$ in 1995 . The concern is heightened because the same trend has been observed in in- 
dustrialized countries, and no one wishes to contemplate the specter of having $15 \%$ of the gross domestic product expended on health, as occurs in the United States of America. Although I have argued elsewhere that there is no ideal level for health expenditure, the reality is that there are opportunity costs of such expenditure. Given the tenuous connection between expenditure in personal care services and health outcomes, the upward trend must be a cause for concern.

Debates about health expenditure usually include consideration of which aspects of health care should be considered as essential public goods and therefore financed by the State, and which are private goods and therefore the concern and responsibility of individuals. This debate is compounded by the fact that the 200 million persons living in poverty in the Americas face the greatest strain in acquiring these private goods.

The absolute expenditure on health, as well as its distribution, naturally varies among the countries. As an example, the percentage of the health expenditure coming from private sources is $73 \%$ in El Salvador and 22\% in Uruguay and Panama. The weighted average is $59.5 \%$ for Latin America and the Caribbean. A remarkable feature is the percentage of private expenditure in the poorest countries. In Haiti, for example, $63 \%$ of health expenditure is private. Approximately two-thirds of the private expenditure is in the forms of direct payment to providers for goods and services. Another remarkable feature of the systems is the growth of that portion of private expenditure going for health insurance. Our estimates are that at last $15 \%$ of the population is affiliated with private insurance systems, and that figure continues to grow. The cause of this growth may be dissatisfaction with social security and other parts of the public sector, an increase in disposable income as the economic situation improved during the past decade, or aggressive promotion by the agencies that offer private insurance.

The expenditure in social health insurance is divided between public traditional social security schemes and private programs. Typical of the large private social insurance schemes is the one in Chile. However, the public institutions administer more than $90 \%$ of all the insurance, and we estimate that this represents close to US $\$ 120$ billion. The potential of this in the context of reform is enormous. But we should note that the coverage by social security varies. In the Dominican Republic only $7 \%$ of the population is covered. As a general rule, where there are higher levels of health spending by social security systems, the health coverage is higher.

The proximity to the United States increases the concern for the rise in costs and the possibility of containing them. Because of the permeability of the images and values of the North, as well as the changing demographic situation of Latin America and the Caribbean, these countries are beginning to experience what medical ethicist Daniel Callahan has described as the "triple dynamic of aging, technological progress, and public demand." More than anything else, this combination has been responsible for the rise in health costs in the United States. The costs of health care at the older extreme of life are higher, and we are constantly being reminded of this as we note the steady graying of the population in Latin America and the Caribbean. The percentage of persons over the age of 60 is already higher in Uruguay than in the United States. But it is the technological imperative driving us to make medicine regard death as a failure that has been a major factor in increasing costs. It will be almost impossible to contain costs if the system gives priority to individual demands rather than needs and fails to recognize that the efforts to satisfy the sum of the individual demands may do damage to the collective good. As Callahan argues, there is only a remote possibility that there will be some magical increase in the efficiency of the systems that will lead to a sustained reduction in the rate of increase of costs. There first must be a major cultural change.

Even in those countries with very low health expenditures, it is now fashionable to examine the increases in health costs with great care. The focus is not so much on the absolute increase in expenditure but on the composition and the ends to which it is put. It is now common to have countries insisting on expenditure for the genuine public goods and emphasizing prevention and promotion, not as cheap alternatives to personal care services but as complements to them.

The final major challenge is related to the role of the State in the provision of health services. What parts of health care should come under the jurisdiction of the State in expressing the collective will of the people, and what should be bartered in the market or be the spoils of a reward system that gives primacy to individual accumulation of various assets? The tendency in Latin America and the Caribbean in the early part of the decade of the nineties was to follow the doctrine of the State retreating to a minimalist position and leaving many areas, such as some aspects of health, to the market. However, there has been considerable rethinking of this position, partly because it is being recognized that the expression "free market" is perhaps oxymoronic, at least in the area of health. There must be another, visible hand of government that regulates the nature of the transactions in the market, which is rarely if ever free. In addition, everyone now agrees that a small State that is more efficient 
and focused on a regulatory rather than an allembracing executing role is perhaps the best for society.

On the basis of those challenges it is possible to outline what might be the future directions of health systems reform in Latin America. The first inescapable need is to monitor the actual situation. If reform of the health system has as one of its goals the improvement of health outcomes, then we must have the means of monitoring those outcomes. The Pan American Health Organization is devoting considerable effort towards having countries on a regular basis collect certain core data on health and related matters and analyze them as the precursor for providing the information for decisions about resource allocation. It is not enough to have national averages. Increasingly, we pay attention to the distribution of various health indicators, since knowledge of distribution makes it possible to target those areas or groups that are most in need. The search for equity as a goal of the health services cannot be realized without data on the distribution of health status and health services.

There is general agreement on the essential features of the reform that needs to take place. I say essential features because the details and the sequence of actions will depend very much on the local situation. The major purpose of reform will be to have the system achieve the goals I have already outlined, that is, equity and social protection, as well as cost control.

I foresee the countries continuing to focus on three major areas: 1) organizing the provision of services, 2) financing, and 3) executing a steering or regulatory role. In collaboration with the U.S. Agency for International Development, PAHO has mounted a major exercise in accordance with the mandate given to us by the 1994 Summit of the Americas to monitor the reform process. The data we have collected from all the countries that are engaged in reform show that their activities are concentrated in three main areas. The division of responsibility for the discharge of functions that pertain to these areas presents one of the greatest challenges. At present, we find in many countries that the three major actors-the ministry of health, social security, and the private sector-are unfortunately involved in all three roles.

In terms of provision of services we see many actors that come from the private sector, the public sector, and the third sector. We do not see this trend as necessarily harmful. In Costa Rica, for example, the provision of services falls mainly to the public and private sectors. And within the public sector, Social Security is the entity chiefly responsible for providing services. In Guatemala the public provision is in the hands of Social Security, the Ministry of Health, and a large number of nongovernmental organizations. The critical issue is to ensure that there is efficiency of production by these actors, with that efficiency in some instances being achieved by competition among the actors for provision of services and adequate supervision.

I see as ideal the development of a single insurer and a single pool of funds for public expenditure that may come from the national resources, as well as social security. The availability of a single source of financing will permit the more equitable reallocation of funds. In this ideal situation, the single public insurer will be in a position to contract with a range of private and public providers of care and to use competition to secure the best possible services.

The success of this depends in large measure on the ability of the State to supply the funds necessary to ensure that there is indeed care for all. I do not discard the possibility or need for there also to be a private insurer that will be in a position to contract for services from the most efficient providers. I do not envisage, however, that we will see in the near future, if ever, a single insurer that incorporates private as well as public funding, pools the risks, and then regulates the delivery of services to ensure universal coverage through a varied set of providers.

"The major purpose of reform will be to
have the system achieve equity and social
protection, as well as cost control."

Decentralization, especially in larger countries, will be the norm, and funding from the national resources of the ministry of health or social security will be allocated for management at the local level. These funds may or may not be complemented by funds generated locally. This has been the basis of the reform of the system in Brazil, which, in addition to decentralization, has emphasized popular participation in the design of services. I note that the incoming Government of Argentina included in its election manifesto the notion of health as a right and promised public insurance that would be decentralized and permit universal and equitable coverage for the entire population.

I see health system reform ensuring a removal of the segmentation that exists in most countries, with the ministry of health, social security, and the private sector duplicating efforts, especially in 
terms of providing and financing services. The ministry will retain and be the sole agent responsible for the regulatory function. Financing, at least of public services, will be the prime responsibility of a new social insurance system that sees solidarity as not being restricted to its membership.

The reformed health systems will have to address the issue of restraining health care cost increases. This will require a combination of such steps as raising the productivity of the existing services, improved management of human resources, better monitoring of care patterns, wider use of treatment guidelines, restraining the indiscriminate use of technology, and rationalizing the use of pharmaceuticals.

The reform of the health system must address the dominant patterns of morbidity and mortality and the changes taking place in Latin America. The chronic diseases are assuming greater importance even while we continue to struggle with malaria, dengue, and tuberculosis. There were an estimated one million cases of malaria and about one quarter of a million cases of tuberculosis in 1998. Epidemics of dengue still occur and bring with them dengue hemorrhagic fever. HIV / AIDS is very much with us, and the countries of the Caribbean show some of the highest prevalence rates in the world. Tobaccorelated illnesses kill almost 400 people daily. I am convinced that the approach to dealing with many of these problems must be based on the proper use of information for change of behavior. Unfortunately, most traditional health professionals are poorly equipped to use this instrument.

However, the major aspect of reform that requires the most attention and is still relatively underappreciated is the regulatory or steering role. That is basically a function of the State and must be performed by the ministry of health. The essence of this steering role is to ensure-rather than provide-universally available services. This implies setting norms of care to ensure quality and devising the basic portfolio of benefits that must be guaranteed to all the population as one fundamental of universal coverage. It also implies establishing policies for the management of the human resources that are needed, as well as the very critical responsibility of discharging the essential public health functions that are related to the population as a whole. Many ministries of health are just coming to grips with their own need for restructuring to ensure the discharge of this regulatory role.

PAHO is currently engaged in a major effort to examine the extent to which these essential public health functions are being discharged in Latin America. There will undoubtedly be some variation, but I have been attracted to those set out in the United States five years ago by the U.S. Department of Health and Human Services. These included: prevention of epidemics and spread of disease, protection from environmental risks, promotion of healthy behaviors, response to disasters and assistance to recovering communities, and assuring the quality and accessibility of health services. I would ask you to note the last function. The State should assure the quality and accessibility of health services, and I would add that they should be available to all.

I can envisage managed care playing an increased role in the reformed health systems. Managed care is a reality, especially in such large countries as Brazil, and is restricted to the private sector. Several managed care organizations here in the United States are said to be eyeing the large quantities of funds now being handled by social security administrations, or that will be handled if countries move towards a single public insurer. The interest,

$$
\begin{aligned}
& \text { "The major aspect of reform that requires } \\
& \text { the most attention and is still relatively } \\
& \text { underappreciated is the regulatory or } \\
& \text { steering role." }
\end{aligned}
$$

of course, comes mainly from the for-profit managed care organizations.

Many of you will have read the articles recently published in the New England Journal of Medi cine that claim that managed care is already firmly entrenched in Latin America. These articles point out the opportunities for financial gain and the fact that managed care has not encountered the widespread negative image that prevails here in the United States. The possibilities are there, but I noted the final phrase of the editorial, which qualified the export as "a new corporate imperialism." The major factors that will determine growth of this approach will be the regulatory and political aspects. Perhaps the most important of these will be the facility given to employers and employees to opt out of the staterun social security system. Another key factor will be the capacity of companies based in the United States to establish commercial linkages with Latin American counterparts.

I am more sanguine about the spread of some of the tools of managed care than about the possibility of massive incursion of for-profit companies from the United States into Latin America, and indeed I do not envisage the Pan American Health Organization facilitating such incursion. I have to be convinced that the more common approaches of 
managed care companies are compatible with our firm orientation towards there being equity in the health system. However, we are actively promoting the idea that the tools that have succeeded in reducing the rate of increase in costs may very well find application in the public as well as privately funded schemes for delivering care. Luckily, the design of such tools and their testing are not uniquely restricted to for-profit managed care organizations. Indeed, the reverse may be the case. Such tools as practice guidelines for clinical patterns, treatment norms, auditing of clinical care, and a renewed emphasis on prevention and promotion as being the responsibility of all loci of care can be profitably applied in all the systems in Latin America. This is irrespective of whether the provider is spending public funds or private funds.

The reform process will not have sustainability unless there is careful monitoring of the process. Some of the elements to be monitored include the evolution of the desegmentation of the system and the effectiveness with which the ministry of health discharges its regulatory role. In addition, there must be a system of national health accounts that allows monitoring of the financial flows into and out of the various parts of the system. One critical area will be the extent to which there is genuine universal coverage and whether the hitherto marginalized groups are being covered. And perhaps the last area will be the establishment of indicators for monitoring the discharge of the essential public health functions by the State.

The process of reform in Latin America and the Caribbean is well under way. While it is evident even now that there are almost as many variations as countries, it is fair to say that they all seek the basic goals mentioned above. Reform is obviously not an end in itself. My vision, or perhaps dream, is that the process now under way will indeed result in better health for all people of the Region of the Americas. And the Pan American Health Organization will do everything in its power to see that that happens. Our technical cooperation will be focused on helping countries to examine carefully the challenges before them, to learn from the experiences of other countries, and to continue to seek equity, which is the essence of Health For All, a call that still remains as an inspiration to seek the health that is necessary for all people. My definition of necessary is nothing less than that articulated by Adam Smith:

By necessaries I understand not only the commodities which are indispensably necessary for the support of life but whatever the custom of the country renders it indecent for creditable people, even of the lowest order, to be without. 